\title{
Reproduction: a global nutritional challenge
}

\author{
BY GAIL R. GOLDBERG
}

\author{
MRC Dunn Clinical Nutrition Centre, Hills Road, Cambridge CB2 2DH
}

Pregnancy, the most anabolic state in adults, and lactation which involves substantial changes in nutrient flux, are physiological states unique to women. The present paper discusses the nutritional issues, using many of our own studies of energy metabolism as examples, which have the greatest impact on the course and outcome of pregnancy and lactation.

\section{GLOBAL DIFFERENCES IN BIRTH RATES AND PARITY}

In developing countries women undergo many cycles of pregnancy and lactation during their reproductive lifespan. Reproductive cycles often start at an early age and take place at short intervals. Between the ages of 15 and 40 years a typical woman will spend half her time pregnant and lactating (World Health Organization, 1991). Globally, there were over 138 million births in 1994 and the vast majority of the world's babies, (124 million), were born to mothers living in the poorest countries (United Nations International Children's Emergency Fund, 1996; Fig. 1(a and b)). Ten reproductive cycles, typical in developing countries, amount to the accretion of more than $100 \mathrm{~kg}$ extra tissue and the production of 3000 litres milk. Global figures about parity and births, when considered in isolation, suggest that women in the poorest countries (who are often chronically malnourished) successfully achieve a high reproductive yield. However, Fig. 1 (c and d) also illustrates that there is a high maternal and infant mortality associated with the many millions of births' each year (World Health Organization, 1991, 1992; United Nations International Children's Emergency Fund, 1996).

\section{MATERNAL AND INFANT MORTALITY}

\section{Maternal mortality}

A maternal death is defined as the death of a woman, irrespective of the cause, while pregnant or within $42 \mathrm{~d}$ of the end of pregnancy. The main direct causes are obstetric haemorrhage $(30 \%)$, puerperal sepsis $(20 \%)$, eclampsia (10-15\%), abortion (7-30\%), and obstructed labour $(5-10 \%)$, all conditions which only occur during pregnancy. Indirect causes are underlying conditions such as anaemia, diabetes, malaria and essential hypertension, which are aggravated by pregnancy. Direct causes together with anaemia account for more than $80 \%$ of maternal deaths in developing countries (World Health Organization, 1991).

Maternal mortality is difficult to estimate because of non-availability of data, underreporting and mis-classification of deaths. It is estimated that worldwide there were 585000 maternal deaths in 1990 (United Nations International Children's Emergency Fund, 1996). Over $99 \%$ of maternal deaths occur in developing countries, predominantly in Asia (55\% of maternal deaths and $61 \%$ of births) and in Africa (40\% of maternal deaths and $20 \%$ of births; Fig. 1 (c)). All developed countries combined account for less than $1 \%$ 

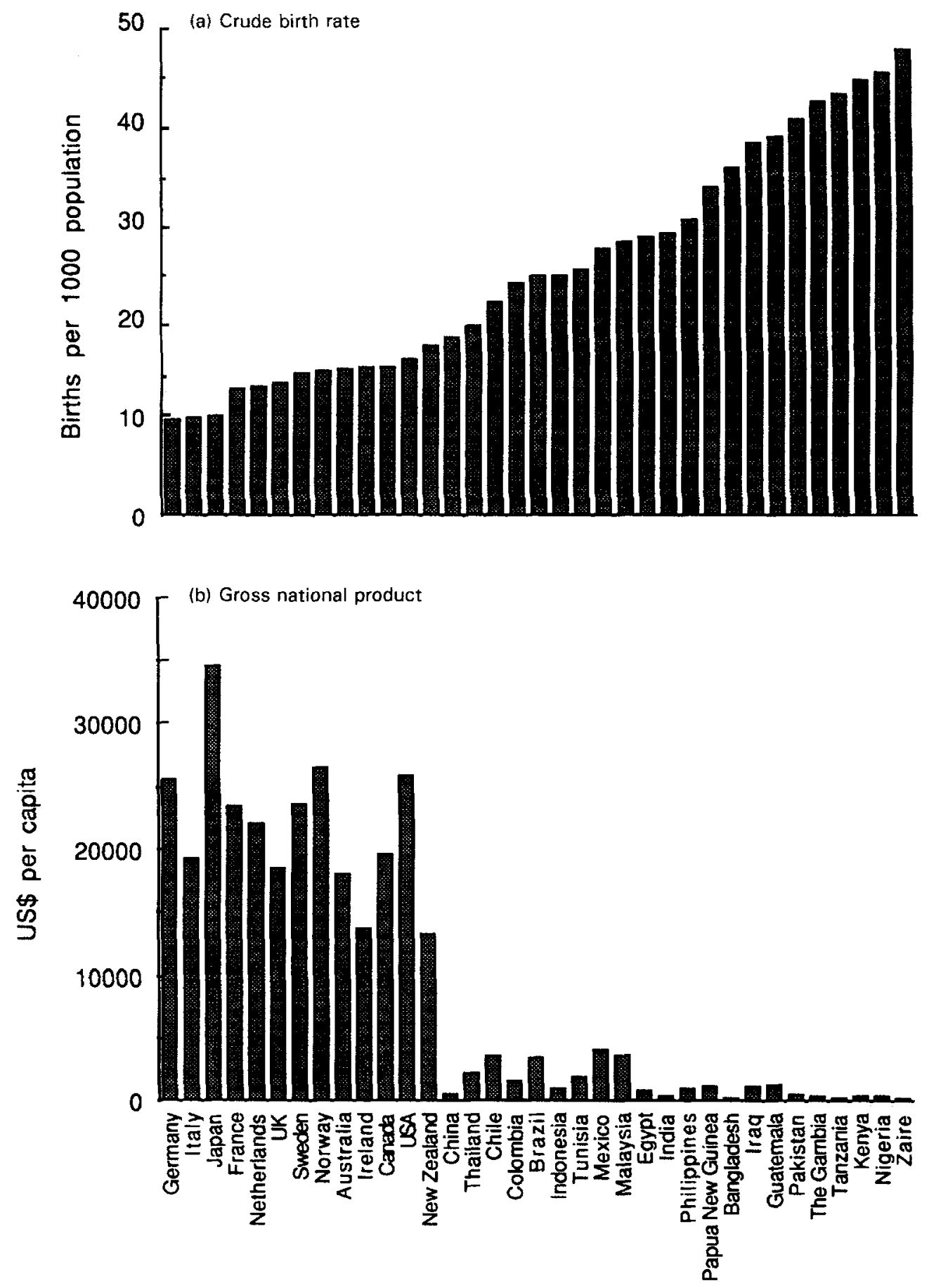

Fig. 1. (a) Crude birth rate, (b) gross national product, (c) maternal mortality rates (deaths per 100000 live births; global 390 , developed countries 30 , developing countries 450), (d) infant mortality rates (deaths per 1000 births; global 71 , developed countries 15 , developing countries 79 ), in a representative selection of developed and developing countries. (From World Health Organization, 1991, 1992). 

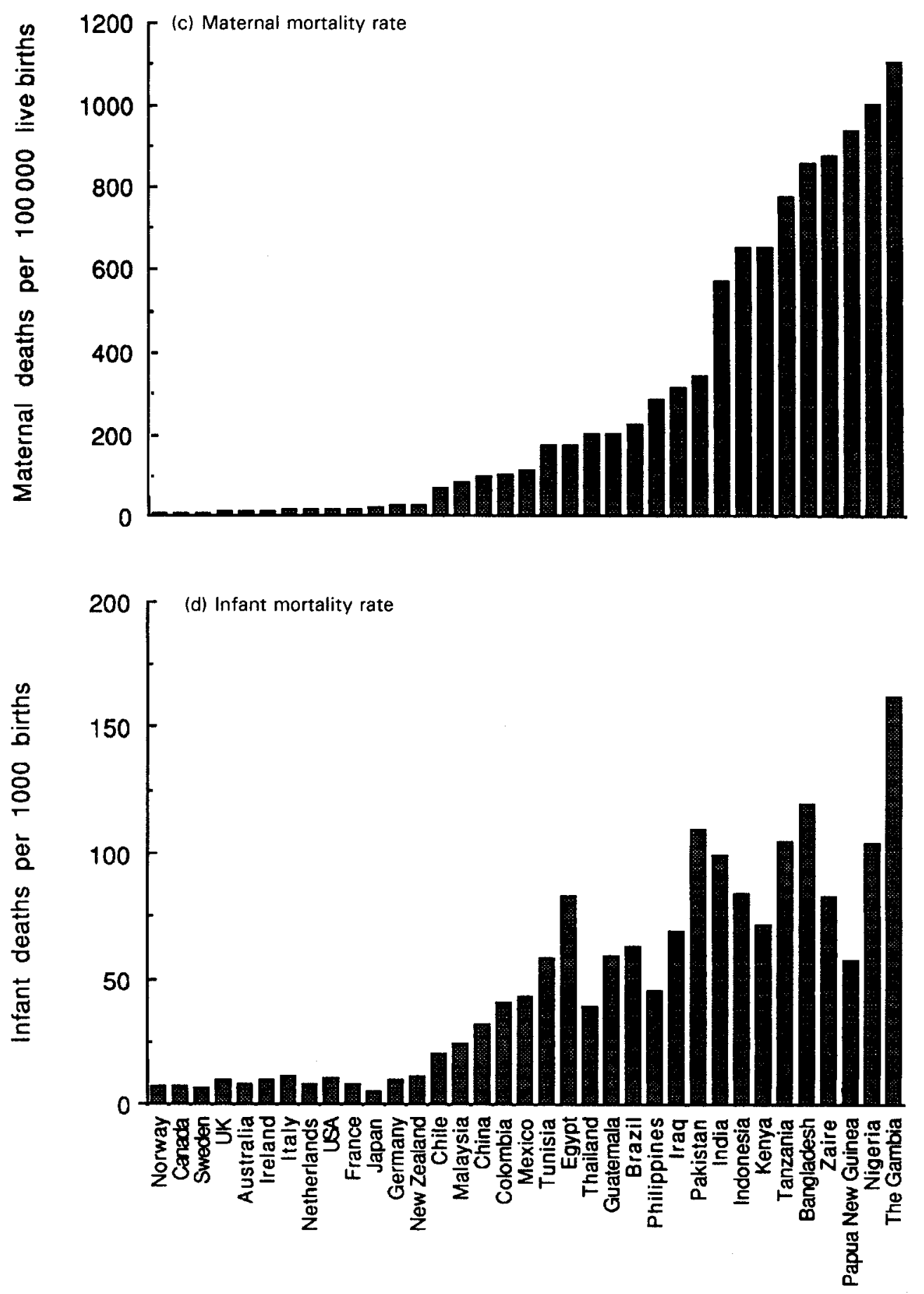

Fig. 1. Continued 


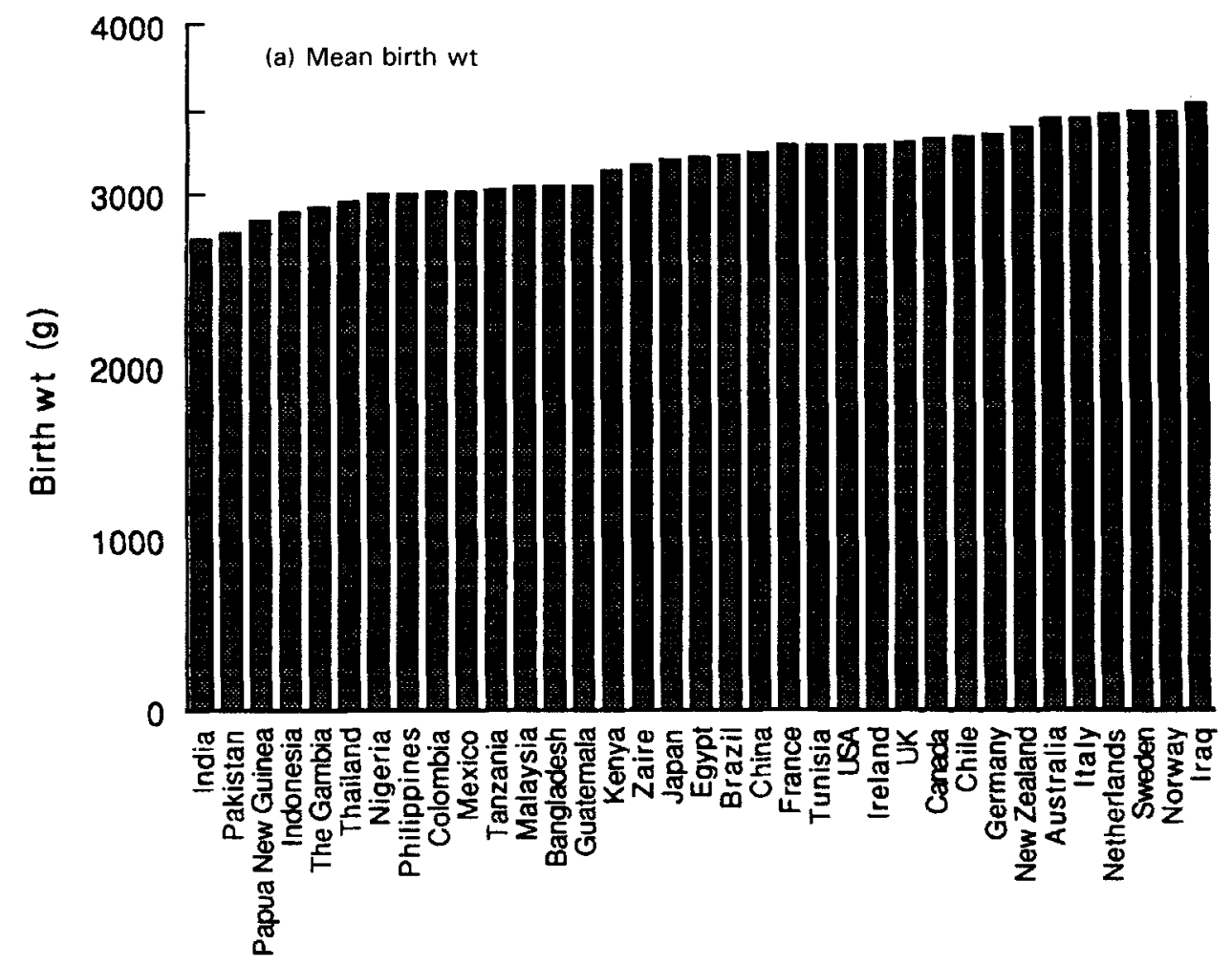

Fig. 2. (a) Mean birth weight and (b) incidence of low birth weight in a representative selection of developed and developing countries (cf. Fig. 1). (From World Health Organization, 1980, 1984.)

of maternal deaths (11\% of all births; World Health Organization, 1991; Court, 1996). In the UK there were 238 maternal deaths between 1988 and 1990 (Keirse, 1994).

Maternal mortality rate (MMR), the number of maternal deaths per 100000 live births, is the indicator which demonstrates the greatest disparity between rich and poor countries (World Health Organization, 1991). It has been calculated that a 66-fold difference in gross national product (GNP) manifests as a nearly 2500 -fold difference in maternal death (Evans, 1995). In many developing countries average MMR is over 1000, whilst in many European countries, North America and Australia the average is 10 (Fig. 2 (c)). It should also be remembered that MMR represents the risk faced by a woman in each pregnancy. Since women in developing countries are of high parity, their lifetime risk can be as high as 1 in 15 . For a woman in a developed country, lifetime risk of maternal death can be as low as 1 in 10000 (World Health Organization, 1991).

\section{Infant mortality}

In 1990 it was estimated that three million infants died in their first week of life, 1.3 million in their first month and 4.8 million in their first year. The global distribution of infant mortality rate (IMR; the number of deaths before the age of 1 year for every 1000 babies born) is similar to MMR (Fig. 1(d)). The majority of infant mortalities occur in Asia (63\%) 


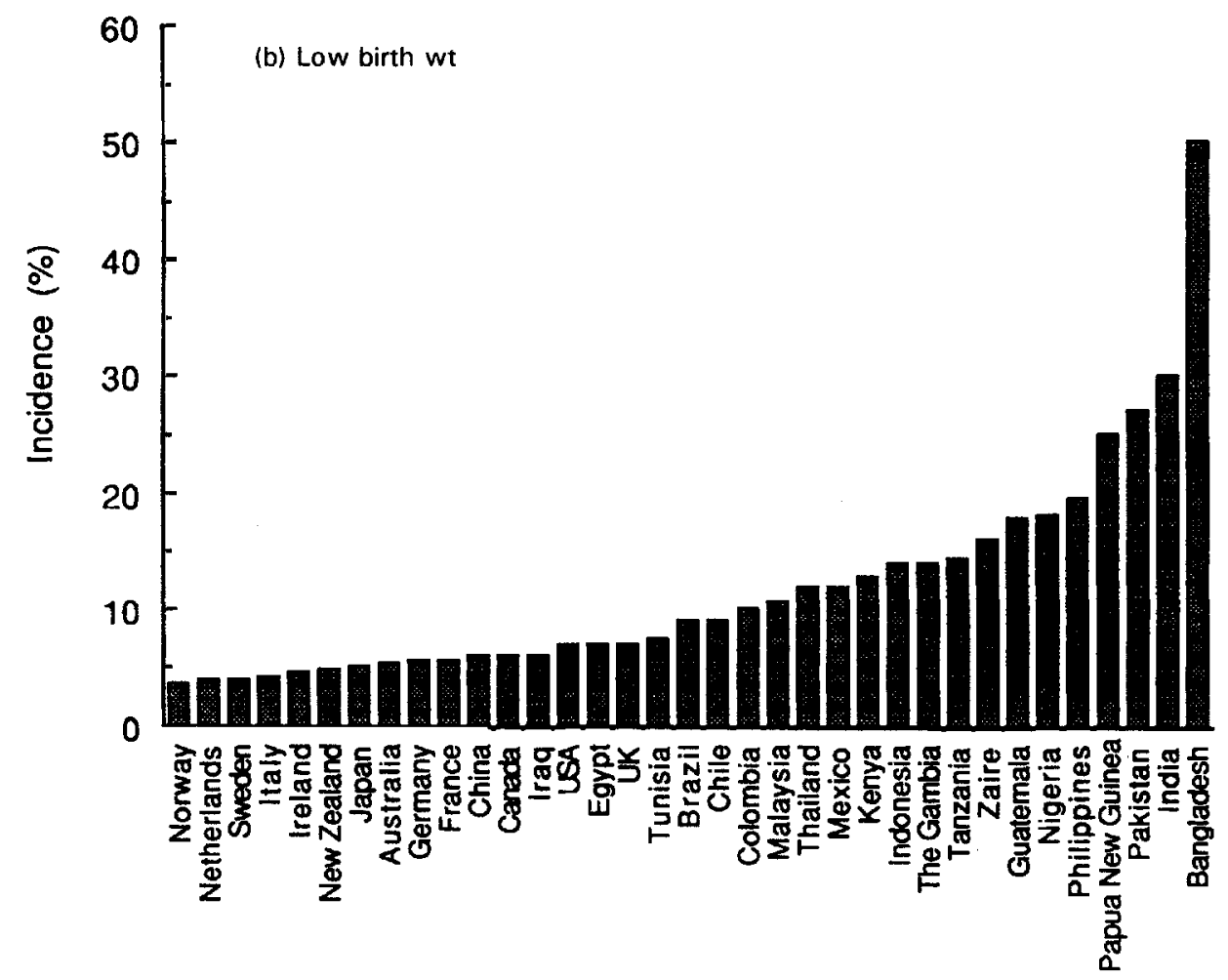

Fig. 2. Continued

and Africa (26\%); all developed countries combined account for $2 \%$ of infant deaths (World Health Organization, 1991; Belsey, 1993).

\section{THE ROLE OF MATERNAL UNDERNUTRITION IN MATERNAL AND INFANT MORTALITY}

\section{Maternal mortality}

In developing countries chronic and acute maternal undernutrition are major contributory factors to both obstructed labour and anaemia (Poppitt \& Prentice, 1993).

The most common cause of obstructed labour is cephalo-pelvic disproportion which is frequently a result of stunting of the mother due to chronic undernutrition during childhood and adolescence. Another cause is physical immaturity because, although fertile, adolescent girls still have $12-18 \%$ of pelvic growth to complete (World Health Organization, 1991). Studies conducted in The Gambia have shown that girls did not reach maximum bone mineral content until aged 24 years, by which time many had completed two or three pregnancies (Lo et al. 1991).

During pregnancy the need for Fe increases 3-fold. In many developing countries the requirement is almost impossible to meet, since women cannot even achieve the nonpregnant requirement. Fe supplementation has been shown to be effective in decreasing the prevalence of anaemia, but there are often problems with supply and compliance (Yip, 1996). Anaemia affects approximately $70 \%$ of pregnant women and is a contributory 
Table 1. Ranked causal factors of intrauterine growth retardation in developing and developed countries (Adapted from Berendes, 1993)

\begin{tabular}{|c|c|c|}
\hline & Developing countries & Developed countries \\
\hline Large impact & $\begin{array}{l}\text { Low energy intake* } \\
\text { Low weight gain* } \\
\text { Low pre-pregnancy weight* } \\
\text { Short stature } \\
\text { Non-white race }\end{array}$ & $\begin{array}{l}\text { Cigarette smoking } \\
\text { Low energy intake* } \\
\text { Low weight gain* } \\
\text { Low pre-pregnancy weight* }\end{array}$ \\
\hline Intermediate impact & $\begin{array}{l}\text { Malaria } \\
\text { Female sex } \\
\text { Primiparity }\end{array}$ & $\begin{array}{l}\text { Primiparity } \\
\text { Female sex } \\
\text { Short stature* } \\
\text { Non-white race }\end{array}$ \\
\hline Small impact & $\begin{array}{l}\text { Maternal LBW* } \\
\text { Previous history of LBW } \\
\text { General morbidity } \\
\text { Small patemal size }\end{array}$ & $\begin{array}{l}\text { Maternal LBW* } \\
\text { Previous history of LBW } \\
\text { General morbidity } \\
\text { Other }\end{array}$ \\
\hline
\end{tabular}

LBW, low birth weight.

*Factors which are directly related to maternal nutritional status.

factor in $20 \%$ of maternal deaths (World Health Organization, 1991). Death results from infection because of lowered resistance to disease, from haemorrhage because of reduced tolerance to blood loss and because anaemic women are greater operative and anaesthetic risks.

\section{Infant mortality}

Worldwide, there is remarkably little variation in human birth weight, mean values only range between a few hundred grams (Fig. 2(a)). However, despite this, birth weight is the single most important determinant of infant survival. Babies weighing less than $3 \mathrm{~kg}$ at birth are up to fifty times more likely to die than those weighing between 3 and $4 \mathrm{~kg}$ (Ashworth \& Feachem, 1985). Infants with birth weights of less than $2.5 \mathrm{~kg}$ have been defined by the World Health Organization (1980) as having low birth weight (LBW). World-wide, $16 \%$ of newborn infants are so classified and more than $90 \%$ are born in developing countries (Fig. 2(b)).

In developed countries, the mean incidence of LBW is about $6.9 \%$ and two-thirds of LBW infants are premature (Belsey, 1993). In developing countries the mean incidence of LBW is $17.6 \%$ and more than $80 \%$ of LBW infants are small-for-gestational age (SGA) because of intrauterine growth retardation (IUGR). Almost all the major causes of IUGR (Table 1) reflect maternal nutritional status before and during pregnancy (Kramer, 1987).

\section{AMELIORATION OF THE EFFECTS OF MATERNAL UNDERNUTRITION}

Body adiposity is an indicator of fitness for reproduction, and fertility is suppressed in severe undernutrition. Once pregnancy is established, extra nutritional requirements have to come from dietary intake and body stores to meet the costs of pregnancy and support the lifestyle of the mother. Fetal growth depends on the health and nutritional status of the mother before conception, the degree of energy demands placed on her during pregnancy, and the growth, energy and nutrient demands of the products of conception at different 
states of gestation (Kramer, 1987). Compared with other mammalian species, the relatively slow rate of fetal growth and large maternal fat stores in human subjects allow the potential for adaptive changes in metabolism to help counter some of the effects of undernutrition (Prentice \& Whitehead, 1987).

The role of adaptive changes in energy metabolism in optimizing fetal growth

Longitudinal studies have shown that individual women in the UK and The Gambia demonstrate a very high level of variability in the metabolic response to pregnancy (Prentice et al. 1989; Goldberg et al. 1993; Poppitt et al. 1993). Compared with baseline pre-pregnant measurements, some women had an immediate and progressive increase in BMR, as expected from theoretical calculations (Hytten, 1991). Others showed a suppression in BMR in early gestation which offset the later increases. These 'energysparing' responses dominated in The Gambia, and in both populations the best predictor of the metabolic response was pre-pregnancy body fat. Analysis of longitudinal studies conducted in other centres also demonstrated that thin marginally-nourished women from developing countries are energy-sparing and that fatter well-nourished affluent women are energy-profligate. Differences in fat accumulation further accentuate the variability in the total metabolic costs of pregnancy which cover a ten-fold range (Fig. 3), but of course do not include energy expended on physical activity. The data suggest that the body has some means of detecting maternal energy status and of modulating physiological responses accordingly. This flexibility appears to be an important mechanism for protecting fetal growth under marginal nutritional conditions (Poppitt et al. 1994). Bronstein et al. (1996) have recently suggested that such mechanisms also operate in the opposite direction and

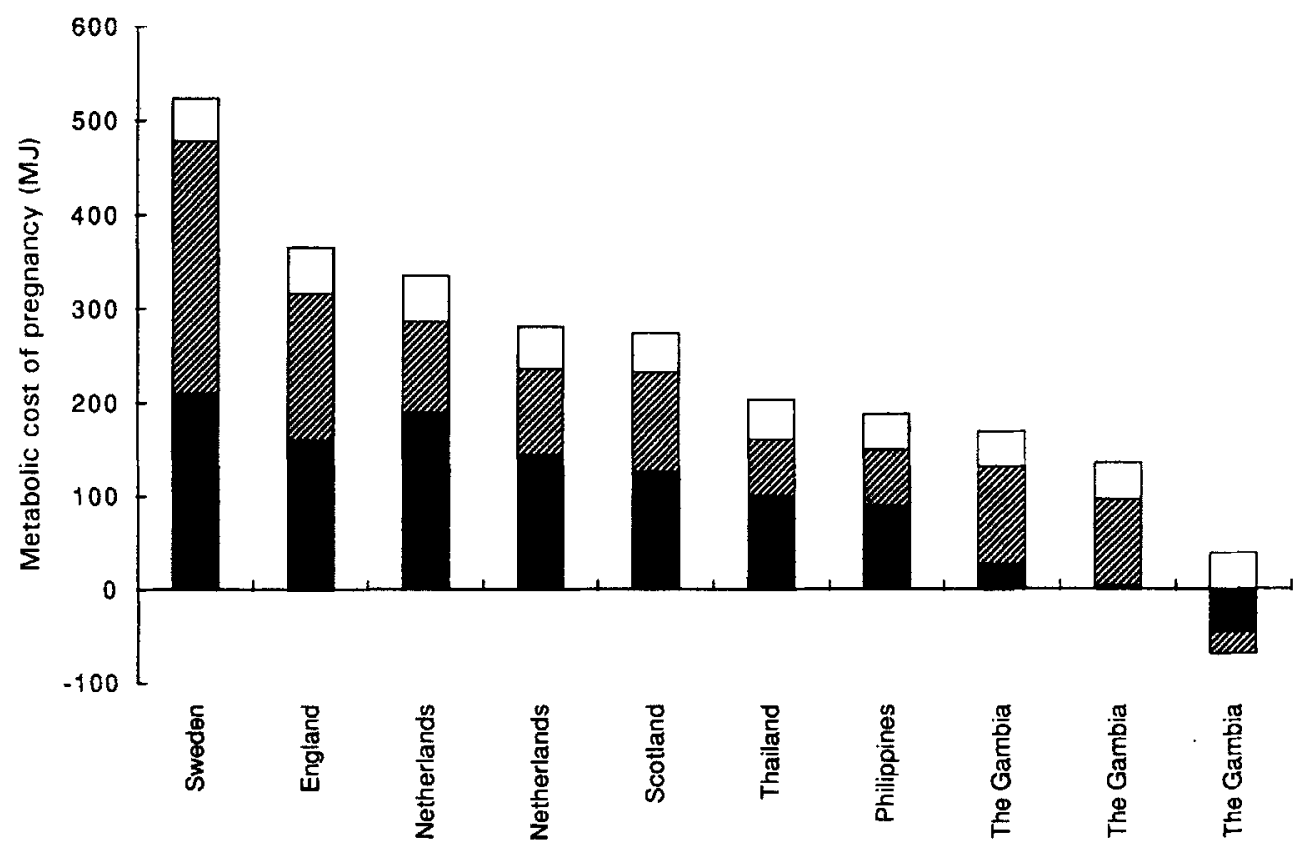

Fig. 3. Meta-analysis of longitudinal studies in which the metabolic costs of nearly 400 pregnancies were measured

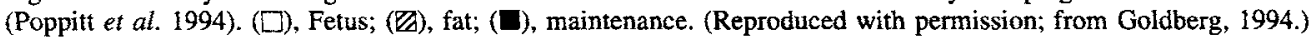


that in obesity, excess fetal growth is prevented by energy-profligate responses to pregnancy.

Whilst reducing physical activity might be a way of saving energy, the women most likely to be able to do this are those from developed countries where sedentary lifestyles restrict the potential to reduce physical activity. In contrast, women in developing countries have much higher levels of physical activity and significant energy-sparing reductions in physical activity are more plausible. However, in these settings the activity is often an obligate feature of survival and studies have demonstrated high levels of physical activity during pregnancy (Prentice et al. 1996).

\section{Dietary supplementation studies}

Since almost all the major causes of IUGR reflect maternal nutrition before and during pregnancy, many factors should be amenable to improved maternal nutrition in the long term (leading to greater stature and higher pre-pregnancy weight) and in the short term (increasing birth weight via increased maternal energy intake and greater gestational weight gains). Many supplementation studies have been conducted and whilst some have shown significant improvements in birth weight, others have not. However, differences in experimental design, amount, timing and frequency of supplementation, choice of target and control groups, and compliance of subjects make comparisons very difficult (Institute of Medicine, 1990).

In The Gambia, adults, including pregnant women, are in severe negative energy balance in the wet season because food from the previous harvest is almost exhausted and levels of physical activity are very high in preparation for the next harvest. Average birth weight decreases by $300 \mathrm{~g}$ and the incidence of LBW and perinatal mortality is very high. In a relatively small-scale trial conducted under strict experimental conditions, Prentice et al. (1987) supplemented pregnant women over a 4-year period. In the wet season average birth weight was significantly increased by over $200 \mathrm{~g}$ and the incidence of LBW significantly reduced from $24 \%$ to $8 \%$. A much larger supplementation trial, conducted via the primary health care system has very recently been completed (Ceesay et al. 1997). Results parallel those of Prentice et al. (1987) and both studies demonstrate that dietary supplementation of pregnant women, when appropriately targeted and effectively carried out, does significantly improve neonatal outcome.

\section{NUTRITIONAL ISSUES FOR PREGNANT WOMEN IN DEVELOPED COUNTRIES}

Even in developed countries, inadequate overall nutrition, Fe deficiency anaemia, low weight gains and LBW infants are major problems for some women, especially those of low socio-economic status (Doyle et al. 1982; Schofield et al. 1987; Institute of Medicine, 1990). Because of this, in the USA the Women Infant and Children (WIC) programme, which is centrally funded, has been running for many years in a number of states.

In the UK, nutritional issues and advice are focused on particular foods or specific nutrients with recommendations that before and/or during pregnancy intakes should be avoided completely (unpasteurized cheeses, raw eggs), reduced (alcohol and foods with a high vitamin A content) or increased (folate and Fe-containing foods or supplements). Although there are recommendations for average energy intakes (Department of Health, 1991), it is impossible to make prescriptive recommendations for individuals because metabolic and behavioural changes are so variable (Goldberg et al. 1993). 
In many developed countries, a major concern is overnutrition during pregnancy, indicated by obesity or excessive weight gains. It is well established that massive obesity is associated with much increased risks of complications (Gross et al. 1980). Galtier-Dereure et al. (1995) have shown that any excess weight before pregnancy is associated with a significantly higher incidence of complications and in-patient hospitalization. Very recently, two studies have reported that obese women are at significantly greater risk of having infants with neural-tube defects, and that, furthermore, the protective effect of taking folic acid appears to be lost (Shaw et al. 1996; Werler et al. 1996). With the upward trend in overweight and obesity in women in developed countries (Seidell, 1995) and the increasing prevalence in developing countries, the incidence of these complications is also likely to increase.

\section{LACTATION}

Whereas pregnancy is universal and the duration almost constant, the prevalence and duration of lactation vary both nationally and internationally. The overall prevalence of lactation is about $50 \%$ in developed countries, but often lower, and duration is typically 3-6 months. Prevalence is much higher in developing countries, in many cases approaching $100 \%$, and duration is typically 18 months (World Health Organization, 1981; White et al. 1992).

\section{FOOD INTAKE AND LACTATION PERFORMANCE}

The energy cost of lactation is about $2.5 \mathrm{MJ} / \mathrm{d}$ in exclusively breast-feeding women (Prentice \& Prentice, 1988). Since this represents a significant proportion of their daily energy intake, it is reasonable to assume that the level of food intake will affect milk output. However cross-country comparisons using data from large numbers of studies and subjects show that lactating women in developed and developing countries produce the same output of milk, typically 700-800 g/d. Furthermore, there is no apparent relationship between maternal BMI and either the output or energy content of breast milk, even at a BMI of $<18.5 \mathrm{~kg} / \mathrm{m}^{2}$, considered to be indicative of chronic undernutrition (Prentice et al. 1994; Prentice \& Prentice, 1995).

\section{THE NUTRITIONAL STRESS OF LACTATION}

Human lactation is a very robust process, milk output and nutrient levels are well protected even at low levels of maternal nutrition and even supplementation of marginally-nourished women has little effect on lactation performance (Prentice \& Prentice, 1995). Compared with other mammals, the nutritional stress of human lactation is very low. Infants, usually singletons, grow very slowly and women only need to produce small volumes of dilute milk relative to other species. Calculations of peak milk energy yield expressed relative to maternal body size have shown that the energy stress of lactation per unit time in human subjects is a small proportion of that for other species which have large litters of fastgrowing young (Prentice \& Whitehead, 1987). By mid-lactation a rat dam is feeding a litter which weighs considerably more than she does, the equivalent of a women feeding a $70 \mathrm{~kg}$ baby.

Compared with most other mammals, women also have substantially greater fat reserves to draw upon to help meet the costs of lactation. Furthermore, whereas the full recommended increment in energy intake is only about $25 \%$ above non-lactating intakes 
(Food and Agriculture Organization/World Health Organization/United Nations University, 1985; Department of Health, 1991) other species, such as rats and sheep have to increase food intake by $400 \%$ (Prentice \& Whitehead, 1987). Some aquatic mammals, such as certain seals, are not able to feed at all during lactation and rely exclusively on fat stores. Women fall between these extremes and the low stress of lactation per unit time allows them to adopt a number of different mechanisms to balance their energy and nutrient budgets.

\section{ADAPTIVE DECREASES IN ENERGY EXPENDITURE}

\section{$B M R$}

Compared with pregnancy there is less evidence to suggest significant energy-sparing decreases in BMR during lactation. A recent review of longitudinal studies concluded that in developed and developing countries, any differences (increases or decreases) in BMR were small (Prentice et al. 1996). However, these may conceal significant energy-sparing adaptations in the mother, because there is an energy cost of milk synthesis, approximately $20 \%$ of the energy transferred in milk (Prentice \& Prentice, 1988). Milk production is assumed to be a continuous process and, therefore, this should be observed as a measurable increase in BMR.

\section{Physical activity}

A number of studies suggest that women in developed countries tend to decrease their moderate and discretionary physical activities (Prentice et al. 1996) and it is not uncommon for women to give up paid employment permanently or for some time postpartum. In a study in which all the components of energy balance were measured, decreases in physical activity met $44 \%$ of the costs of lactation. Women became more physically active as lactation progressed, increasing from physical activity levels (PAL) of $1.50 \times \mathrm{BMR}$ at 4 weeks to 1.59 at 12 weeks, compared with a post-weaning PAL of 1.66 (Goldberg et al. 1991). In contrast, in developing countries, although some cultures have a traditional period of confinement post-partum, many lactating women are obliged to maintain high levels of physical activity, with PAL of 2.0 under some conditions (Prentice et al. 1996).

Nutritional status before and during pregnancy influences the ability of the mother to meet the energy costs of lactation. The biological function of extra fat deposited during pregnancy is presumed to be to help buffer the energy costs. Women who do not deposit fat or who have to mobilize it during pregnancy, therefore, have reduced energy reserves at the beginning of lactation. Whilst this should not pose a problem for women who are able to increase food intake or reduce physical activity (typically in developed countries), the women least likely to have these options are those in developing countries.

Despite higher levels of physical activity and lower levels of energy intake, women in developing countries do manage to sustain successful lactation for long periods. However, the protection of breast-milk quantity and quality which is very important for the infant, is often achieved at the expense of maternal stores. Even though lactation seems to be unaffected by maternal nutritional status at the levels studied, there has to be a threshold of severe undernutrition below which the mother cannot sustain both lactation and her own survival. 


\section{LONGER-TERM CONSEQUENCES OF NUTRITIONAL STATUS AND REPRODUCTION}

\section{Consequences for the mother}

A birth interval of at least 2 years is advocated in developing countries to allow a woman's body time to recover from the extra demands of pregnancy and lactation (Royston \& Armstrong, 1989; World Health Organization, 1992). It has been suggested that frequent reproductive cycles are a cause of poor maternal nutritional status because a rapid succession of pregnancies increasingly depletes maternal resources. However, differing study designs and definitions of what constitutes a reproductive cycle mean that the evidence for 'maternal depletion syndrome' is equivocal (Merchant \& Martorell, 1988).

In contrast, in developed countries there is the potential for quite the opposite effect. Because of changes in lifestyle, body composition and energy intake, pregnancy and lactation are risk periods for the development of obesity, and are likely to be contributory factors to the increasing prevalence of obesity in women (Lederman, 1993; Smith et al. 1994; Boardley et al. 1995). A number of studies have also shown that gestational diabetes predisposes to the development of non-insulin-dependent diabetes mellitus in later life (Catalano et al. 1986; Dornhorst et al. 1990; Damm et al. 1996; Peters et al. 1996).

\section{Consequences for the infant}

LBW infants have an increased risk of remaining malnourished. In developing countries, 5 and $10 \%$ of children are severely wasted at 1 and 2 years of age respectively. By the age of 1 year, $20 \%$ of children are stunted, increasing to $35 \%$ at 2 years, and many children become stunted adults.

Although the major nutritional issues in pregnancy differ between developed and developing countries, the potential for nutritional programming is common to both. Recent epidemiological studies, particularly in the UK, have suggested that adverse nutritional experiences in utero, especially undernutrition, have a powerful influence on the development of conditions such as impaired glucose tolerance and hypertension in adulthood (Barker, 1992; Goldberg \& Prentice, 1994). The studies also suggest that it is not only weight at birth which is important, but other variables such as ponderal index, limb, head and trunk circumferences and placental size. With respect to overnutrition, infants of obese mothers or those who were diabetic during pregnancy are at greater risk of developing obesity and diabetes (Pettitt et al. 1985; Leikin et al. 1987; Neggers et al. 1995; Vohr et al. 1995).

\section{THE GLOBAL CHALLENGES}

This paper has focused on the different issues which depend on nutritional status and lifestyle. Globally, populations have been defined according to whether they live in developed or developing countries. However, for individual women, the nutritional challenges posed by pregnancy and lactation may be quite similar. Because of the high MMR and IMR and the challenges posed by differences in maternal nutritional status, pregnant and lactating women should still be considered as nutritionally at risk.

The low maternal mortality in developed countries is relatively new. As recently as 75 years ago in Europe, North America and Australasia, pregnancy and childbirth were as hazardous as they are for women in developing countries today (Fig. 4; Loudon, 1992). The situation in the last century was even worse. As in many contemporary developing countries (World Health Organization, 1991; Belsey, 1993), death in childbirth and infant 


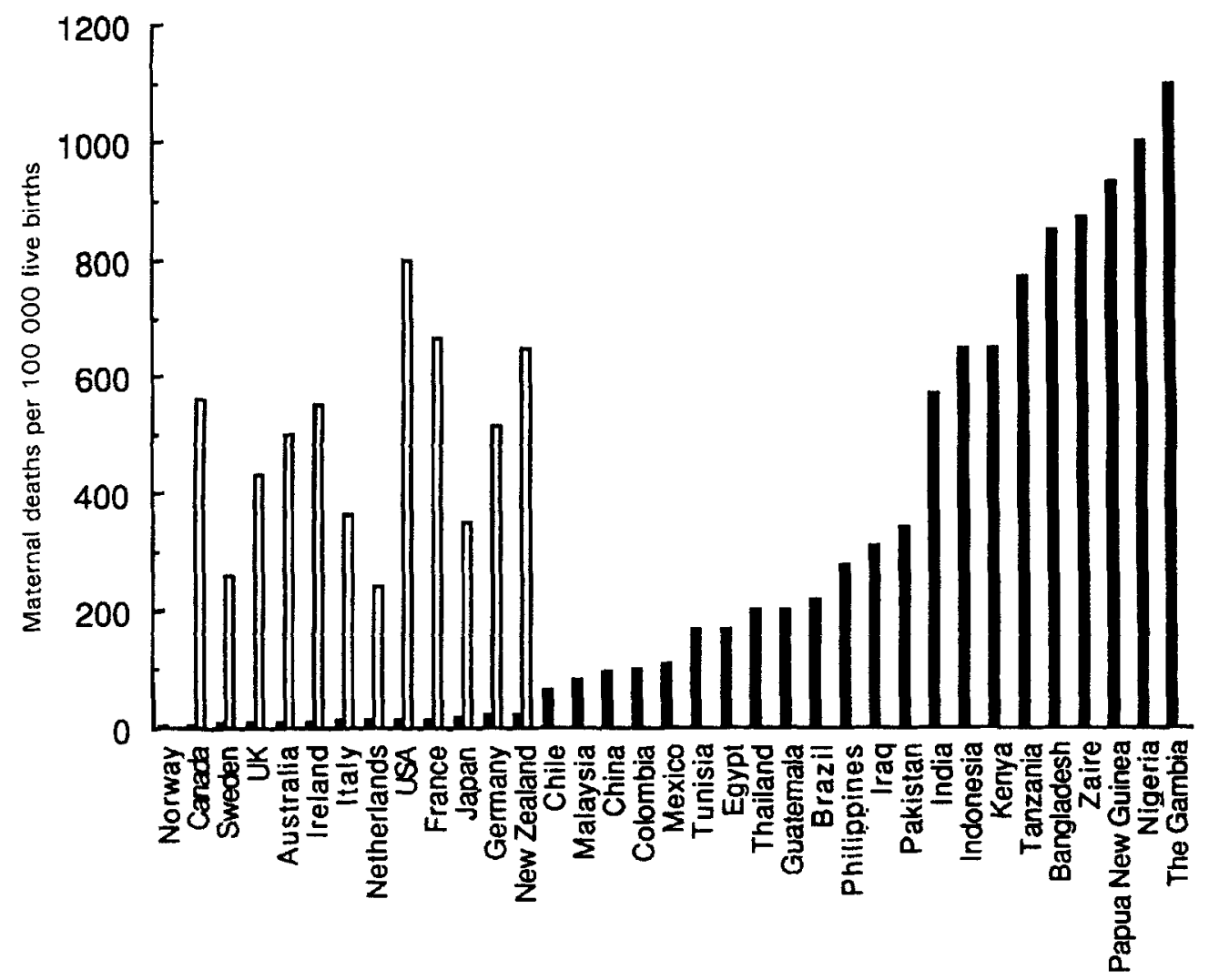

Fig. 4. Contemporary maternal mortality rates (cf. Fig. 1(c); $\mathbf{E}$ ), and rates from some developed countries in 1920 (D) (From Loudon, 1992; United Nations International Children's Emergency Fund, 1996.)

mortality were accepted and expected. In London in 1871 , maternal mortality rates of 200 500 for women delivering at home, and of 800-3500 for those in hospital, were recorded (Dunn, 1996).

The major causes of maternal mortality have always been the same. The reduction this century, and the low risks of pregnancy now enjoyed by women in developed countries are due to a number of factors. General improvements in living and working conditions, cultural and lifestyle changes, medical advances, and improved nutrition have all led to healthier populations. Antenatal and intra-partum monitoring, and safe abortions and Caesarean sections have further contributed to the reduction in maternal mortality. There are currently many initiatives being conducted under the auspices of organizations such as World Health Organization and United Nations International Children's Emergency Fund to make pregnancy and childbirth safer and improve the long-term prognosis of mothers and infants (Royston \& Armstrong, 1989; World Health Organization, 1992; United Nations International Children's Emergency Fund, 1996). The challenge for nutritionists is to help determine the most effective interventions and strategies which will lead to similar reductions in maternal and infant mortality in today's developing countries. 


\section{REFERENCES}

Ashworth, A. \& Feachem, R. G. (1985). Interventions for the control of diarrheal diseases among young children - prevention of low birth weight. Bulletin of the World Health Organization 63, 165-184.

Barker, D. J. P. (editor) (1992). In Fetal and Infant Origins of Adult Disease. London: British Medical Journal.

Belsey, M. A. (1993). Child health and development: health of the new-born. In Birth Risks, pp. 1-24 [J. D. Baurr, editor]. New York: Raven Press.

Berendes, H. W. (1993). Maternal determinants of perinatal mortality and of intrauterine growth retardation and preterm delivery. In Birth Risks, pp. 47-58 [J. D. Baum, editor]. New York: Raven Press.

Boardley, D. J., Sargent, R. G., Coker, A. L., Hussey, J. R. \& Sharpe, P. A. (1995). The relationship between diet, activity and other factors and postpartum weight change by race. Obstetrics and Gynecology 86, 834838.

Bronstein, M. N., Mak, R. P. \& King, J. C. (1996). Unexpected relationship between fat mass and basal metabolic rate in pregnant women. British Journal of Nutrition 75, 659-668.

Catalano, P. M., Bernstein, I. R., Wolfe, R. R., Srikanta, S., Tyzbir, E. \& Sims, E. A. H. (1986). Subclinical abnormalities of glucose metabolism in subjects with previous gestational diabetes. American Journal of Obstetrics and Gynecology 155, 1255-1262.

Ceesay, S. M., Prentice, A. M., Cole, T. J., Foord, F., Weaver, L. T., Poskitt, E. \& Whitehead, R. G. (1997). Improved fetal growth and reduced perinatal mortality following maternal dietary supplementation in a primary health care setting in rural Gambia. American Joumal of Clinical Nutrition (In the Press).

Court, C. (1996). WHO claims maternal mortality has been underestimated. British Medical Journal 312, 398.

Damm, P., Vestergaard, H., Kuhl, C. \& Pedersen, O. (1996). Impaired insulin-stimulated nonoxidative glucose metabolism in glucose tolerant women with previous gestational diabetes. American Journal of Obstetrics and Gynecology 174, 722-729.

Department of Health (1991). Dietary Reference Values for Food Energy and Nutrients for the United Kingdom. London: H. M. Stationery Office.

Dornhorst, A., Bailey, P. C., Anyaoku, V., Elkeles, R. S., Johnston, D. G. \& Beard, R. W. (1990). Abnormalities of glucose tolerance following gestational diabetes. Quarterly Journal of Medicine 284, 1219-1228.

Doyle, W., Crawford, M. A., Laurance, B. M. \& Drury, P. (1982). Dietary survey during pregnancy in a low socio-economic group. Human Nutrition: Applied Nutrition 36A, 95-106.

Dunn, P. M. (1996). Florence Nightingale (1820-1910): maternal mortality and the training of midwives. Archives of Diseases in Childhood 74, F219-F220.

Evans, I. (1995). SAPping maternal health. Lancet 346, 1046.

Food and Agriculture Organization/World Health Organization/United Nations University (1985). Report of a Joint Expert Consultation: Energy and Protein Requirements. Technical Report Series no. 724. Geneva: WHO.

Galtier-Dereure, F., Montpeyroux, F., Boulot, P., Bringer, J. \& Jaffiol, C. (1995). Weight excess before pregnancy: complications and cost. International Journal of Obesity 19, 443-448.

Goldberg, G. R. (1994). Human pregnancy and lactation: Physiological, metabolic and behavioural strategies to maintain energy balance. British Nutrition Foundation Nutrition Bulletin no. 19, Suppl. 37-52.

Goldberg, G. R. \& Prentice, A. M. (1994). Maternal and fetal determinants of adult diseases. Nutrition Reviews 52, 191-200.

Goldberg, G. R., Prentice, A. M., Coward, W. A., Davies, H. L., Murgatroyd, P. R., Sawyer, M. B., Ashford, J. \& Black, A. E. (1991). Longitudinal assessment of the components of energy balance in well-nourished lactating women. American Journal of Clinical Nutrition 54, 788-798.

Goldberg, G. R., Prentice, A. M., Coward, W. A., Murgatroyd, P. R., Davies, H. L., Wensing, C., Black, A. E., Harding, M. \& Sawyer, M. (1993). Longitudinal assessment of energy expenditure in pregnancy by the doubly-labelled water method. American Journal of Clinical Nutrition 57, 494-505.

Gross, T., Sokol, R. J. \& King, K. C. (1980). Obesity in pregnancy: Risks and outcomes. Obstetrics and Gynecology 56, 446-450.

Hytten, F. E. (1991). Nutrition. In Clinical Physiology in Obstetrics, 2nd ed., pp. 150-172 [ F. E. Hytten and G. Chamberlain, editors]. Oxford: Blackwell Scientific Publications.

Institute of Medicine (1990). Subcommittee on Nutritional Status and Weight Gain During Pregnancy. Nutrition During Pregnancy. part I, Weight Gain; part II, Nutrient Supplements. Washington, DC: National Academy Press.

Keirse, M. J. N. C. (1994). Maternal mortality: stalemate or stagnant. British Medical Journal 308, 354 355.

Kramer, M. S. (1987). Determinants of low birth weight: methodological assessment and meta-analysis. Bulletin of the World Health Organization 65, 663-737.

Lederman, S. A. (1993). The effect of pregnancy weight gain on later obesity. Obstetrics and Gynecology 82 , $148-155$. 
Leikin, E. L., Jenkins, J. H., Pomerantz, G. A. \& Klein, L. (1987). Abnormal glucose screening tests in pregnancy. A risk factor for fetal macrosomia. Obstetrics and Gynecology 69, 570-573.

Lo, C. W., Jarjou, L. M. A., Poppitt, S. D., Cole, T. J., Neer, R. \& Prentice, A. (1991). Delayed development of bone mass in West African adolescents. In Osteoporosis 90: Third International Symposium on Osteoporosis, vol. 1, pp. 73-77 [C. Christiansen and K. Overgaard, editors]. Aalborg, Denmark: Handelstrykkerier Aalborg Aps.

Loudon, I. (1992). Death in Childbirth. An International Study of Maternal Care and Maternal Mortality 1800 1950. Oxford: Clarendon Press.

Merchant, K. \& Martorell, R. (1988). Frequent reproductive cycling, does it lead to nutritional depletion of mothers? Progress in Food and Nutrition Science 12, 339-369.

Neggers, Y., Goldenberg, R. L., Cliver, S. P., Hoffman, H. J. \& Cutter, G. R. (1995). The relationship between maternal and neonatal anthropometric measurements in term newborns. Obstetrics and Gynecology 85, 192 196.

Peters, R. K., Kjos, S. L., Xiang, A. \& Buchanan, T. A. (1996). Long-term diabetogenic effect of single pregnancy in women with previous gestational diabetes mellitus. Lancet 347, 227-230.

Pettitt, D. J., Bennett, P. H., Knowler, W. C., Baird, H. R. \& Aleck, K. A. (1985). Gestational diabetes mellitus and impaired glucose tolerance during pregnancy. Long-term effects on obesity and glucose tolerance in the offspring. Diabetes 34, Suppl. 2, 119-122.

Poppitt, S. D. \& Prentice, A. M. (1993). Maternal nutritional deficiencies in developing countries. In Birth Risks, pp. 71-82 [J. D. Baum, editor]. New York: Raven Press.

Poppitt, S. D., Prentice, A. M., Goldberg, G. R. \& Whitehead, R. G. (1994). Energy-sparing strategies to protect human fetal growth. American Journal of Obstetrics and Gynecology 171, 118-125.

Poppitt, S. D., Prentice, A. M., Jequier, E., Schutz, Y. \& Whitehead, R. G. (1993). Evidence of energy-sparing in Gambian women during pregnancy: a longitudinal study using whole-body calorimetry. American Journal of Clinical Nutrition 57, 353-364.

Prentice, A. M., Cole, T. J., Foord, F. A., Lamb, W. H. \& Whitehead, R. G. (1987). Increased birthweight following prenatal dietary supplementation of rural African women. American Journal of Clinical Nutrition 46, $912-925$.

Prentice, A. M., Goldberg, G. R., Davies, H. L., Murgatroyd, P. R. \& Scott, W. (1989). Energy-sparing adaptations in human pregnancy assessed by whole-body calorimetry. British Journal of Nutrition 62, 5-22.

Prentice, A. M., Goldberg, G. R. \& Prentice, A. (1994). Body mass index and lactational performance. European Journal of Clinical Nutrition 48, Suppl. 3, S78-S89.

Prentice, A. M. \& Prentice, A. (1988). Energy costs of lactation. Annual Review of Nutrition 8, 63-79.

Prentice, A. M. \& Prentice, A. (1995). Evolutionary and environmental influences on human lactation. Proceedings of the Nutrition Society 54, 391-400.

Prentice, A. M., Spaaij, C. J. K., Goldberg, G. R., Poppitt, S. D., van Raaij, J. M. A., Totton, M., Swann, D. \& Black, A. E. (1996). Energy requirements of pregnant and lactating women. European Journal of Clinical Nutrition 50, Suppl. 1, S82-S111.

Prentice, A. M. \& Whitehead, R. G. (1987). The energetics of human reproduction. Symposia of the Zoological Society of London 57, 275-304.

Royston, E. \& Armstrong, S. (editors) (1989). In Preventing Maternal Deaths. Geneva: WHO.

Schofield, C., Wheeler, E. \& Stewart, J. (1987). The diets of pregnant and post-pregnant women in different social groups in London and Edinburgh. British Journal of Nutrition 58, 369-381.

Seidell, J. C. (1995). Obesity in Europe: Scaling an epidemic. International Journal of Obesity 19, Suppl. 3, S1S4.

Shaw, G. M., Velie, E. M. \& Schaffer, D. (1996). Risk of neural tube defect-affected pregnancies among obese women. Journal of the American Medical Association 275, 1093-1096.

Smith, D. E., Lewis, C. E., Caveny, J. L., Perkins, L. L., Burke, G. L. \& Bild, D. E. (1994). Longitudinal changes in adiposity associated with pregnancy: The CARDIA Study. Journal of the American Medical Association 271, 1747-1751.

United National International Children's Emergency Fund (1996). The Progress of Nations: The Nations of the World Ranked According to Their Achievements in Child Health, Nutrition, Education, Family Planning and Progress for Women. New York: UNICEF.

Vohr, B. R., McGarvey, S. T. \& Coll, C. G. (1995). Effects of maternal gestational diabetes and adiposity on neonatal adiposity and blood pressure. Diabetes Care 18, 467-475.

Werler, M. M., Louik, C., Shapiro, S. \& Mitchell, A. A. (1996). Prepregnant weight in relation to risk of neural tube defects. Journal of the American Medical Association 275, 1089-1092.

White, A., Freeth, S. \& O'Brien, M. (1992). Infant Feeding 1990. London: H. M. Stationery Office.

World Health Organization (1980). The incidence of low birth weight: a critical review of available information. World Health Statistics Quarterly 33, 197-224.

World Health Organization (1981). Contemporary Patterns of Breast-feeding. Report on the WHO Collaborative Study on Breast-feeding. Geneva: WHO. 
World Health Organization (1984). The incidence of low birthweight: an update. Weekly Epidemiological Record 59, 205-212.

World Health Organization (1991). Maternal Mortality: A Global Factbook. Geneva: WHO.

World Health Organization (1992). Reproductive Health: A Key to a Brighter Future. Geneva: WHO.

Yip, R. (1996). Editorial. Iron supplementation during pregnancy: is it effective? American Joumal of Clinical Nutrition 63, 853-855. 